REVIEW

\title{
Male circumcision and risk of syphilis, chancroid, and genital herpes: a systematic review and meta-analysis
}

\author{
H A Weiss, S L Thomas, S K Munabi, R J Hayes
}

Sex Transm Infect 2006;82:101-110. doi: 10.1136/sti.2005.017442

See linked commentary on p 110

See end of article for authors' affiliations

.....................

Correspondence to: Dr H A Weiss, MRC

Tropical Epidemiology

Group, Infectious Disease

Epidemiology Unit, Keppel

Street, London WC1E 7HT,

UK; helen.weiss@lshtm.ac. uk

Accepted for publication 27 September 2005

\begin{abstract}
Objectives: Male circumcision is associated with reduced risk of HIV infection. This may be partly because of a protective effect of circumcision on other sexually transmitted infections (STI), especially those causing genital ulcers, but evidence for such protection is unclear. Our objective was to conduct a systematic review and meta-analyses of the associations between male circumcision and infection with herpes simplex virus type 2 (HSV-2), Treponema pallidum, or Haemophilus ducreyi.

Methods: Electronic databases (1950-2004) were searched using keywords and text terms for herpes simplex, syphilis, chancroid, ulcerative sexually transmitted diseases, or their causative agents, in conjunction with terms to identify epidemiological studies. References of key articles were hand searched, and data were extracted using standardised forms. Random effects models were used to summarise relative risk (RR) where appropriate.

Results: 26 articles met the inclusion criteria. Most syphilis studies reported a substantially reduced risk among circumcised men (summary $R R=0.67,95 \%$ confidence interval $(\mathrm{Cl}) 0.54$ to 0.83 ), although there was significant between study heterogeneity $(p=0.01)$. The reduced risk of HSV-2 infection was of borderline statistical significance (summary $\mathrm{RR}=0.88,95 \% \mathrm{Cl} 0.77$ to 1.01 ). Circumcised men were at lower risk of chancroid in six of seven studies (individual study RRs: 0.12 to 1.11).

Conclusions: This first systematic review of male circumcision and ulcerative STI strongly indicates that circumcised men are at lower risk of chancroid and syphilis. There is less association with HSV-2. Potential male circumcision interventions to reduce HIV in high risk populations may provide additional benefit by protecting against other STI.
\end{abstract}

M ale circumcision is one of the oldest surgical procedures and is almost universal among Muslim and Jewish men and in some ethnic groups in subSaharan Africa. In the late 19th century, lower disease prevalence among Jews in the United Kingdom was ascribed to circumcision, which became increasingly common in English speaking industrialised countries as physicians advocated it for preventing a range of conditions. ${ }^{1}$ By the mid-20th century, neonatal male circumcision was routine in many parts of the United States and New Zealand, and was common in Australia ${ }^{2}$ and Canada. ${ }^{3}$ Rates in these countries subsequently fell as medical organisations found no clear medical indication for neonatal circumcision. ${ }^{4}$

The potential association between male circumcision and sexually transmitted diseases (STDs) was first reported in 1855 , in a study where $61 \%$ of non-Jewish compared with $19 \%$ of Jewish STD patients had syphilis. ${ }^{5}$ Later studies supported this finding, reporting higher than expected proportions of uncircumcised men among case series of genital herpes, ${ }^{6}$ syphilis, ${ }^{37}$ chancroid, ${ }^{7-9}$ and gonorrhoea. ${ }^{37}$ Similar observations were reported at a meeting of traditional healers in South Africa in $1992^{10}$ and in a study of circumcision practices in Mwanza. ${ }^{11}$

In 1998, Moses et al ${ }^{12}$ reviewed the evidence for male circumcision as a preventive health measure and concluded that circumcised men had a lower risk of diseases such as chancroid, syphilis, and genital herpes. However, in 1999 another review found little evidence of an association with these infections, ${ }^{13}$ and the American Academy of Pediatrics concluded that the evidence was "complex and conflicting." ${ }^{\prime 4}$

In contrast, there is clear evidence that circumcised men are at significantly lower risk of acquiring HIV infection, ${ }^{14-16}$ probably because the inner surface of the foreskin contains numerous Langerhan's cells and CD4+ T lymphocytes (primary HIV-1 target cells), ${ }^{17}$ and because of the warm, moist environment under the foreskin. ${ }^{18}{ }^{19}$ The latter could also facilitate infection with other sexually transmitted pathogens. The protective effect of circumcision on HIV is especially strong among populations more highly exposed to sexually transmitted infections (STIs), suggesting that part of the effect on HIV may be mediated via protection against other STIs that facilitate HIV transmission. ${ }^{14}$

The aim of this paper was to review systematically the evidence for an association between male circumcision and infection with ulcerative STIs, herpes simplex virus type 2 (HSV-2), Treponeum pallidum, and Haemophilus ducreyi (the causative agents of syphilis and chancroid).

\section{METHODS}

\section{Study selection}

We searched PubMed and Embase for papers published in any language between 1950 and April 2004. In PubMed, search terms for the outcomes of interest included the exploded MeSH terms "herpes simplex," "syphilis," "chancroid," "Herpesvirus2, Human," "Treponema pallidum," "Haemophilus ducreyi," and "sexually transmitted diseases" (the latter combined with the MeSH term "ulcer") and the free text terms "genital herpes," "HSV2," "HSV-2," "syphilis," "chancroid," "chancre," or "ducreyi." We did not include circumcision as a search term to minimise ascertain-
Abbreviations: $\mathrm{Cl}$, confidence interval; FTA-ABS, fluorescent treponemal antibody absorbed test; GUD, genital ulcer disease; HSV, herpes simplex virus; LGV, lymphogranuloma venereum; RPR, rapid plasma regain test, RR, relative risk; STD, sexually transmitted diseases; STI, sexually transmitted infections; TPHA, Treponema pallidum haemagglutination assay; TPPA, Treponema pallidum particle agglutination; TRUST, toludidine red unheated serum test; VDRL, Venereal Disease Research Laboratory Slide Test 


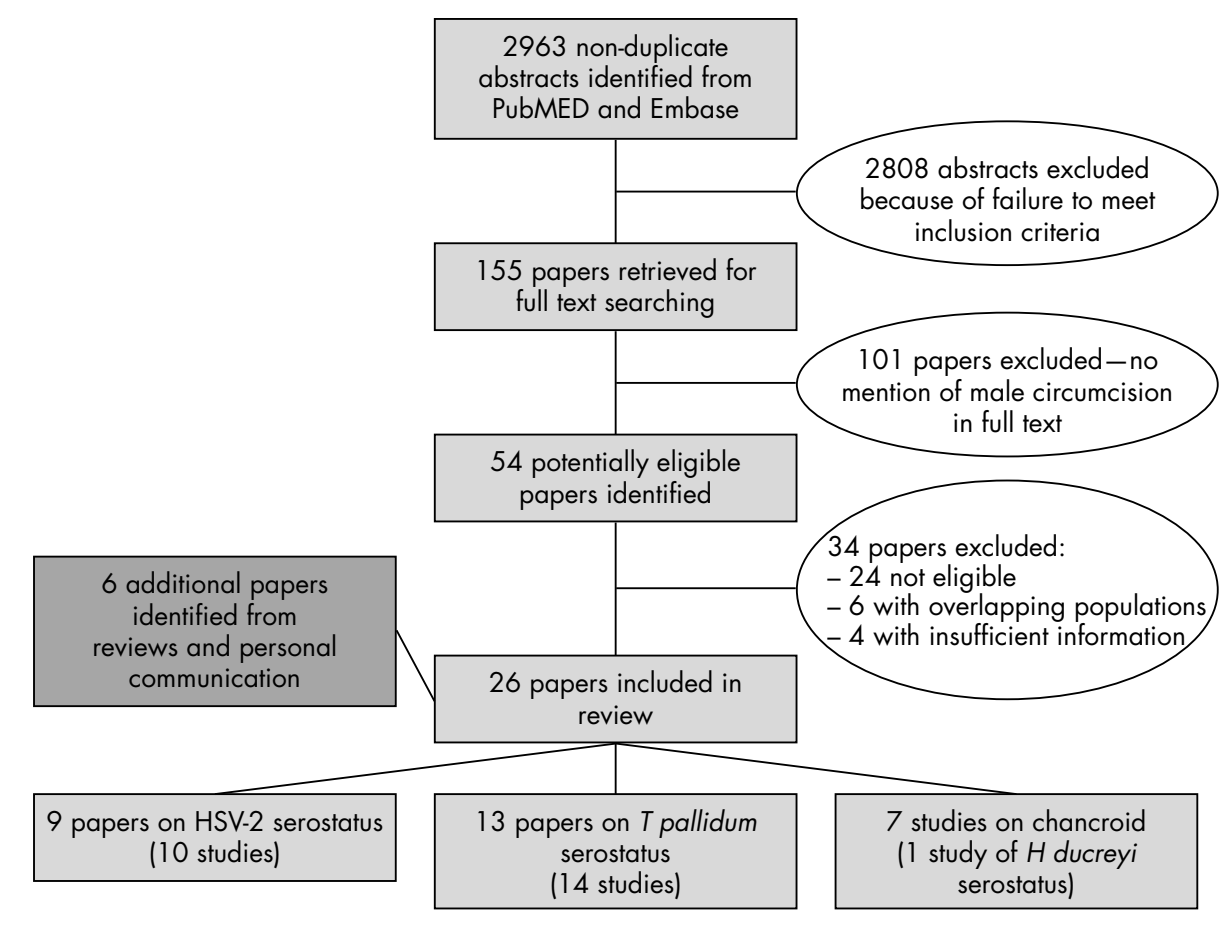

Figure 1 Flow chart of study selection for inclusion in the systematic review.

ment bias, as authors may be more likely to mention circumcision in the abstract if they found an association. Instead, we searched for articles with the outcomes of interest plus any of the MeSH terms "epidemiologic studies," "seroepidemiologic studies," "risk factors," "odds ratio," "prevalence," "incidence," "risk," or "multivariate analysis," or the free text terms "prevalence" or "incidence." Similar terms were used for searching Embase. We checked the reference lists of all relevant papers, and of previously published reviews of circumcision and STIs. ${ }^{12}{ }^{13}$ Additional information was sought where necessary from authors.

Each identified abstract was reviewed independently by two authors (SM, HW). We were interested in the effect of circumcision on acquisition of infection rather than on clinical disease because, for example, circumcision may plausibly protect against HSV-2 infection but is unlikely to affect the risk of recurrences of genital herpes once infected. Further, there is potential for selection bias in studies of clinically diagnosed disease, as circumcised men may be more likely to notice and seek treatment for infections with relatively painless ulcers (such as syphilis), resulting in a possible underestimate of any true effect. Hence, studies were restricted in the first instance to those with the selected outcomes based on serological evidence of infection, not disease. We excluded studies among women; studies from countries where overall prevalence of circumcision is either extremely high or very low $(<5 \%$ or $>95 \%$ prevalence) or where more than $99 \%$ of the population is Muslim (as these were unlikely to be informative), case series of genital ulcer disease (GUD) patients or HIV positive individuals, and studies of syphilis without confirmatory treponemal tests, as non-treponemal tests tend to have poor specificity. ${ }^{20}$

The effect of male circumcision on STIs among STD clinic attenders is subject to selection bias. Comparing circumcision rates among men with one STI versus another could underestimate any true effect if circumcision protects against several STIs (as has been suggested), because the comparison group may have a lower circumcision rate than the background population. ${ }^{12}$ To minimise such selection biases, we limited the meta-analyses to studies in which the comparison groups were asymptomatic clinic attenders or seronegative individuals.

Studies whose abstracts indicated analysis of risk factors for either HSV-2 seropositivity or past/recent infection with syphilis or chancroid were eligible for full text searching, as were HIV risk factor studies that mentioned male circumcision, as these could have also included data on circumcision and other STIs. Study populations that appeared in more than one publication were included only once, choosing the publication with the more informative study design or that controlled most fully for confounders.

\section{Data extraction}

For each study, we extracted the following data using a standardised sheet: authors, country, year(s) of study, study design, proportion circumcised, method of ascertaining circumcision status, proportion with STI of interest, method of STI diagnosis, HIV prevalence, statistical methods used, crude and adjusted risk ratios, and other quality issues (participation rates, loss to follow up, confounders adjusted for). In studies where circumcision was assessed by both self report and genital examination, the latter was used. Where possible, we re-analysed data to compare STI risk in uncircumcised men with those circumcised before reported age at first sex. Circumcision in the United States, Peru, and Australia was assumed to have occurred neonatally.

\section{Statistical methods}

Effect sizes (relative risk, RR) were estimated with rate ratios for cohort studies, prevalence ratios or odds ratios for cross sectional studies, and odds ratios for case-control studies. Where the RR was not presented but raw data were available, the RR and 95\% confidence interval (CI) were calculated. The "best" effect estimate (adjusted RR where available, otherwise unadjusted RR) was included in a random effects metaanalysis. ${ }^{21}$ This calculates a weighted average log RR, with weights inversely proportional to the sum of the "within study" and "between study" variance. Sensitivity analyses were carried out restricting meta-analyses to studies that (1) adjusted for confounding by age and at least one measure of 


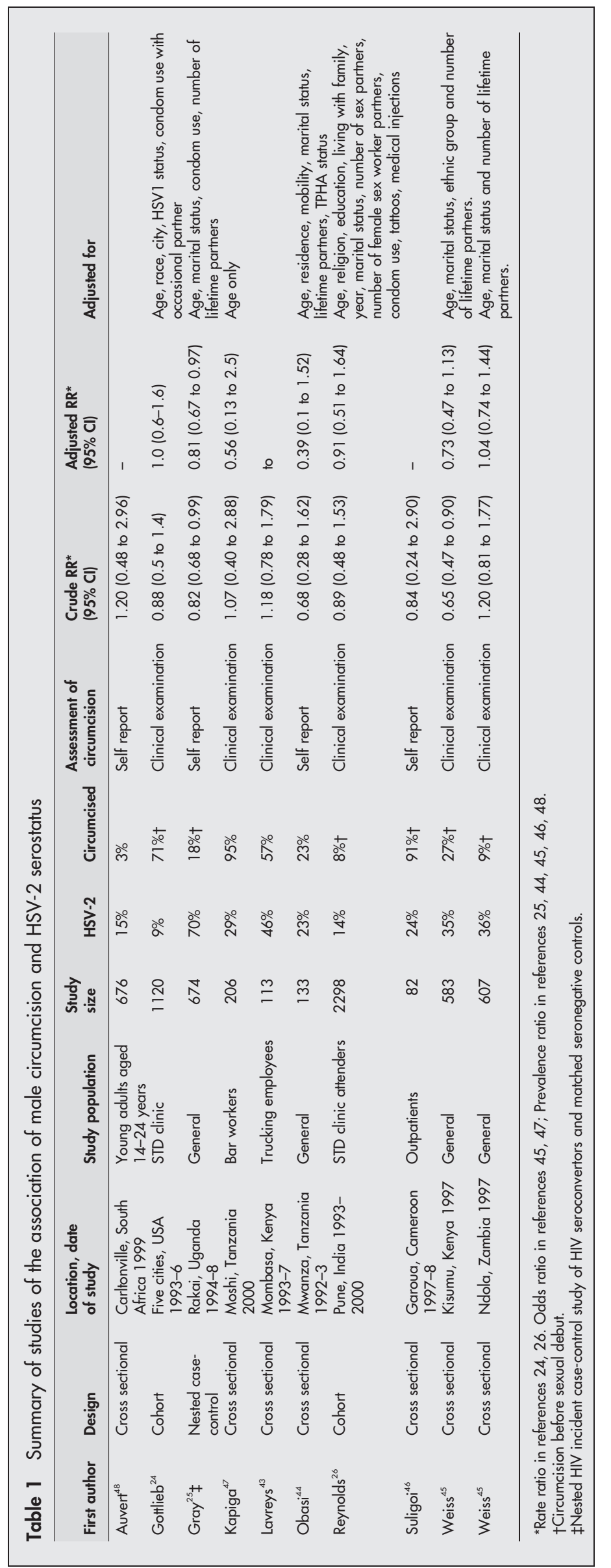


sexual behaviour; (2) ascertained circumcision status by examination; (3) (for syphilis studies) estimated lifetime infection with syphilis (initial screening with treponemal tests) rather than recent/active infection; (4) allowed us to estimate whether circumcision had occurred before sexual debut (and therefore before infection) for all participantsthat is, studies where men are circumcised neonatally, or where reported age at circumcision and age at sexual debut are given; (5) were in populations of heterosexual men. Publication bias was assessed with funnel plots and Begg's test ${ }^{22}$ for correlation between the effect estimates and their variances. Statistical and graphical analyses were carried out using Stata 8.2. ${ }^{23}$

\section{RESULTS}

\section{Results of search strategy}

In total, 2963 non-duplicate articles were identified from database searches, of which 155 were eligible for full text searching (fig 1). Of these, 54 included male circumcision in the text and data were extracted. Six authors publishing relevant but insufficient data provided further analyses which enabled inclusion of their studies in the review, including three further eligible papers, ${ }^{24-26}$ which were in press at the time of our search. Twenty four papers were excluded because they were not eligible after data extraction, six were excluded because their study populations overlapped with other papers in the review,,$^{27-32}$ and four contained insufficient information to be included. ${ }^{33-36}$ Only one study with serological evidence of past infection with Haemophilus ducreyi was identified, ${ }^{37}$ and so all studies of chancroid diagnosed clinically or microbiologically are presented..$^{78-42} \mathrm{~A}$ total of 26 papers incorporating 28 studies were included in the systematic review. Three papers included both HSV-2 and syphilis as outcomes..$^{25} 23$

\section{Association of male circumcision and HSV-2 seropositivity}

Ten eligible studies of HSV-2 seropositivity were identified; eight from Africa, one from India, and one from the United States. ${ }^{24-26}{ }^{43-48}$ Six studies were among men at generally low risk for STIs (general populations, outpatients) and four were among men at higher risk of STIs (bar workers, truck drivers, and STD clinic attenders). Participation rates ranged from
$43 \%{ }^{24}$ to $100 \%{ }^{46}$ in the seven studies that reported these, and were greater than $70 \%$ in four studies. Loss to follow up was $25 \%$ and $36 \%$ in the two cohort studies. ${ }^{24} 26$

Circumcised men were at lower risk of HSV-2 seropositivity than uncircumcised men on univariable analysis in six studies (table 1), and the association was statistically significant $(\mathrm{p}<0.05)$ in three of these. ${ }^{24} 2545$

Seven studies included a RR with some adjustment for confounding. ${ }^{24-26}$ 44-47 These all adjusted for age, and all but one $^{47}$ adjusted for several other potential confounders including sociodemographic factors, sexual behaviour, and other risk factors (table 1). The "best" estimate RRs ranged from 0.39 to 1.20 , and the random effects summary RR was 0.88 (CI 0.77 to 1.01; p value for homogeneity $=0.57$; fig $2 \mathrm{~A}$ ).

Results were similar when restricted to studies that adjusted for age and at least one measure of sexual behaviour (summary $\mathrm{RR}=0.85$, CI 0.74 to 0.98 ), or those where circumcision occurred before first sexual intercourse (summary $\mathrm{RR}=0.86$, CI 0.74 to 0.99 ). The effect of circumcision was less protective among the six studies, ${ }^{24} 26434547$ which assessed circumcision by genital examination compared with those which asked for self report ${ }^{25} 44^{46}$ (summary $\mathrm{RR}=0.97$, CI 0.80 to 1.17 versus $\mathrm{RR}=0.8 \mathrm{l}$, CI 0.68 to $0.98)$, although this difference was not statistically significant $(p=0.18)$. Restricting analyses to studies that used a rate ratio or prevalence ratio (because HSV-2 infection is common in these populations, and so the OR may not closely estimate the RR) made little difference (summary $R R=0.89$, CI 0.78 to 1.02 ). There was little evidence of publication bias $(\mathrm{p}=0.72$; fig $3 \mathrm{~A})$.

Six studies examined the effect of male circumcision on both HIV and HSV-2.25 $26^{43-45}$ Among these studies, the magnitude of association between circumcision and HIV ( summary $\mathrm{RR}=0.34$; CI 0.18 to 0.62 ) was about twice that for HSV-2 (summary RR $=0.69$; CI 0.46 to 1.03 ).

\section{Association of male circumcision and syphilis seropositivity}

Fourteen studies examined the association between male circumcision and serological evidence of syphilis infection (table 2), from sub-Saharan Africa (nine studies), the United States (two studies), Australia, India, and Peru. The outcome was lifetime infection (initial TPHA screening) in six
A

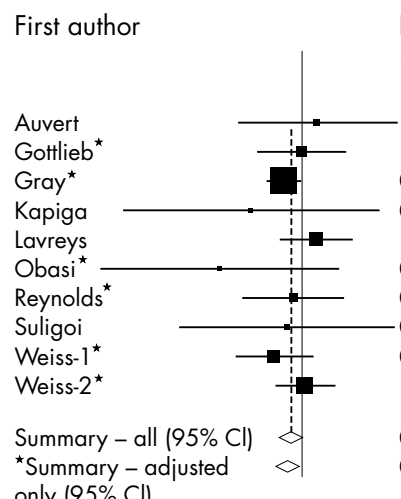

only $(95 \% \mathrm{Cl})$

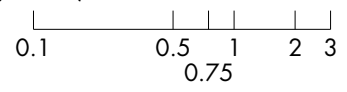

Relative risk
B

Relative risk First author (95\% Cl)

$1.20(0.48$ to 2.96$)$ Buve- 1 $1.00(0.60$ to 1.67$)$ Buve- $2^{\star}$ $0.81(0.67$ to 0.98$)$ Bwayo $0.56(0.13$ to 2.41$)$ Cook $^{*}$ $1.18(0.78$ to 1.79$)$ Diseker $0.39(0.10$ to 1.52$)$ Gray $^{\star}$ $0.91(0.51$ to 1.62 ) Lavreys 0.84 (0.24 to 2.90$)$ Newell $^{\star}$ $0.73(0.47$ to 1.13$)$ Parker $^{\star}$ 1.04 (0.74 to 1.46$)$ Reynolds 0.88 (0.77 to 1.01$)^{\text {Tabet }^{\star}}$ $0.85(0.74$ to 0.98$)$ Urassa* Urassa Summary - all $(95 \%$ Cl) *Summary-adjusted $\longleftrightarrow \quad 0.69(0.50$ to 0.94$)$ only $(95 \% \mathrm{Cl})$

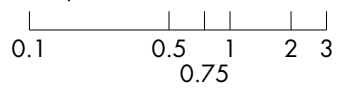

Relative risk
Figure 2 Relative risk (RR) of circumcision status with (A) HSV-2 and (B) syphilis seropositivity. The square and horizontal line corresponds to the $\mathrm{RR}$ and $95 \% \mathrm{Cl}$ for each study. The area Relative risk (95\% Cl) $0.00(0.00$ to 1.21$)$ of the square reflects the weight of each $0.54(0.21$ to 1.39$)$ study. The summary RRs are shown by $0.69(0.51$ to 0.94$)$ the diamonds.

0.25 (0.12 to 0.52$)$

$0.52(0.16$ to 1.69$)$

$1.01(0.76$ to 1.35$)$

0.64 (0.34 to 1.18 )

$0.60(0.40$ to 0.90$)$

0.19 (0.05 to 0.72$)$

0.63 (0.31 to 1.28)

0.78 (0.22 to 2.77$)$

0.70 (0.37 to 1.32$)$

0.95 (0.79 to 1.14 )

0.71 (0.45 to 1.12)

\section{3}

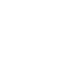



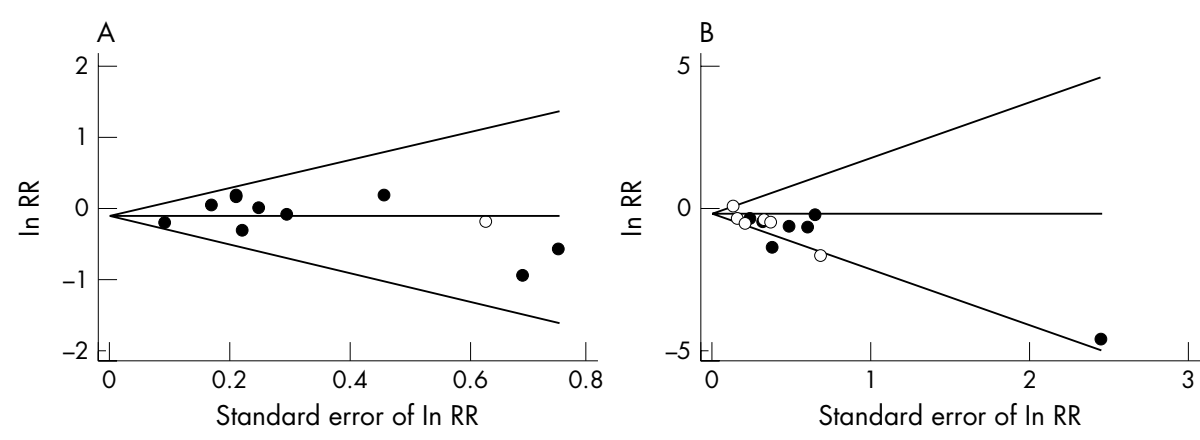

studies, ${ }^{43}{ }^{49-53}$ and more recent infection (initial RPR screening with TPHA confirmation) in the remainder. ${ }^{25} 2653-58$ Prevalence ranged from 2-3\% among STD clinic attenders from the United States to $25 \%$ for past syphilis among truck drivers from Kenya. Participation rates ranged from $43 \%$ to $86 \%$ in the seven studies with available information, and were more than $70 \%$ in three studies. Loss to follow up in the cohort studies was $26 \%$ and $28 \%$, respectively. ${ }^{26} 55$

Eleven studies included some adjustment for potential confounders (table 2). The "best" estimates varied from zero to 1.01 , and five showed statistically significant reduced risk. The random effects summary RR was 0.67 (CI 0.54 to 0.83 ; fig 2B), but with evidence of between study heterogeneity $(\mathrm{p}=0.01)$. The summary RR was little altered when analyses were restricted to studies that assessed circumcision by genital examination, studies among heterosexual men, or studies that included some adjustment for confounding ( summary RR $=0.69$, CI 0.50 to 0.94 ), but the effect was stronger among men for whom circumcision occurred before first sexual intercourse $(\mathrm{RR}=0.53$, CI 0.34 to 0.83 ; $\mathrm{p}$ for effect modification compared with later circumcision $=0.15 ; 2526435153-56)$. The association among studies of lifetime infection (initial TPHA screening) was similar to that overall, although there was less heterogeneity $(\mathrm{p}=0.08)$.

The funnel plot was asymmetrical (fig $3 \mathrm{~B}$ ) with the two largest studies finding the least protective effects ${ }^{25}{ }^{49}$ ( $p$ value for Begg's test $=0.10$ ).

\section{Association of male circumcision and chancroid}

Seven studies examined the association between male circumcision and chancroid (table 3). Three were from Kenya and the remainder from the United States, United Kingdom, and the US and Australian military. ${ }^{70}{ }^{38-42}$ Six of seven studies found a reduced risk of chancroid among circumcised men, and this was statistically significant in four studies (table 3)..$^{3841} 42$ No meta-analysis for the chancroid studies was carried out because (1) the definition and ascertainment of the outcome varied between studies, and (2) the comparison groups varied considerably and some included men with other STIs (mainly urethritis) against which circumcision may also be protective. ${ }^{12}{ }^{13}$

The single study with a serological outcome found no association with circumcision (table 3 ). ${ }^{37}$ Three early studies that compared chancroid patients (diagnosed by clinical diagnosis or microbiology) or penile ulcer patients with asymptomatic controls found that circumcised men were at much lower risk (RR from 0.04 to 0.40). ${ }^{78} 39$ Two more recent studies compared $H$ ducreyi culture positive patients ${ }^{40}$ or GUD patients $(89 \%$ clinically diagnosed as having chancroid $)^{41}$ with urethritis patients. Each found a slightly weaker association than those with asymptomatic controls. The five studies that reported response rates were retrospective record based studies, and so had 100\% responses. ${ }^{78-40} 42$
Figure 3 Funnel plots to detect publication bias in the meta-analysis of circumcision with (A) HSV-2 and (B) syphilis seropositivity. The horizontal line indicates the summary log RR, and guidelines to assist in visualising the funnel are plotted at the $95 \%$ pseudoconfidence limits for this estimate.

\section{DISCUSSION}

\section{Review of findings}

Our results suggest that male circumcision is associated with a reduced risk of ulcerative STIs, especially syphilis and chancroid. All included studies are observational, and their limitations need consideration. However, as discussed below, many potential biases tend to underestimate an association, indicating that the true association may be stronger than the summary RRs presented.

Most included studies assessed circumcision status through a clinical examination, but longitudinal studies from Tanzania ${ }^{11}$ and the United States ${ }^{55}$ have indicated substantial misclassification of status even by examination. However, ascertainment of circumcision status generally occurred before knowledge of serological status and so misclassification is likely to be non-differential, which might underestimate any association.

The selected outcomes in this review were primarily based on serological evidence of infection, not disease. However, serological studies are also subject to misclassification. For example, there are concerns about the validity of commercial HSV-2 assays in samples from African populations ${ }^{59}$ and about the validity of serological tests for $H$ ducreyi. We identified only one study of $H$ ducreyi serostatus, which used an ELISA developed from lipo-oligosacharide. This test has high sensitivity and specificity for detecting $H$ ducreyi antibodies in patients with culture proved chancroid, ${ }^{3760}$ but is not commonly used. Further, the specificity for this test was assessed in a Canadian population and, as for HSV-2 assays, it is not clear that results can be extrapolated to other populations. In addition, misclassification of serostatus is likely to be non-differential with respect to circumcision status, and will thus underestimate any association.

The summary RR for syphilis should be interpreted cautiously, as there was significant heterogeneity between studies. Five of the nine studies of recent or active syphilis screened initially with a non-trepenomal test, confirming seropositives using a treponemal test. This means that some controls may have been TPHA seropositive, and this nondifferential misclassification of outcome may underestimate any protective effect of circumcision. However, the summary RR was similar for past infection as for recent/active infection. The single study among homosexual men found a relatively weak effect (table 2 ) as might be expected because circumcision status is irrelevant to T pallidum infection for the receptive partner.

Some of the heterogeneity was caused by the null effect seen in two large population based African studies, ${ }^{25} 49$ compared with a highly protective association among STD clinic attenders in the United States and Australia. ${ }^{51}{ }^{54}$ One likely explanation for this heterogeneity is age at circumcision. In studies from the United States, Peru, and Australia, almost all men are likely to have been circumcised in infancy or early childhood. ${ }^{54}$ In contrast, the median age at 


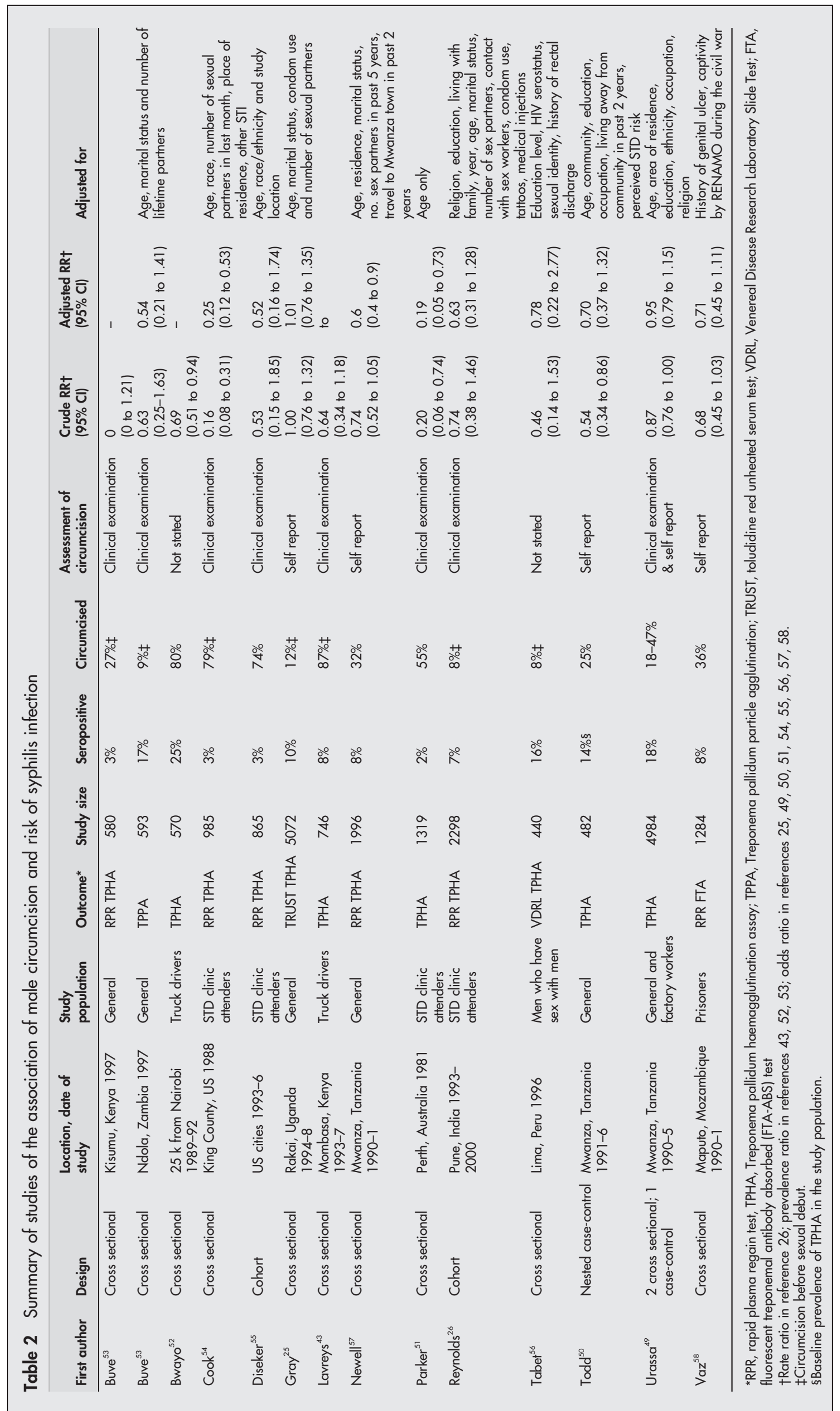




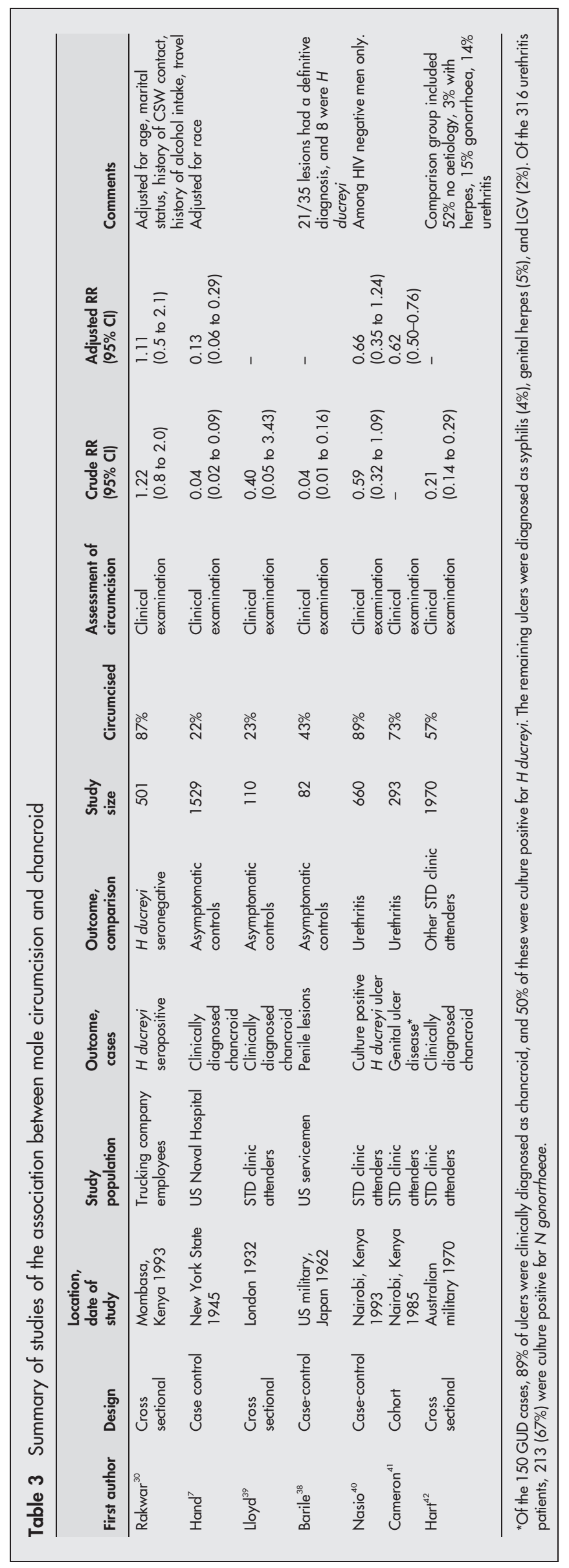


circumcision was 16 and 17 respectively in the studies from South Africa, ${ }^{48}$ and Mwanza, Tanzania. ${ }^{11}$ For cross sectional and case-control studies in populations which tend to circumcise at puberty or later, some men are likely to have become infected with an STI (especially HSV-2 which has high incidence among youth) before becoming circumcised. This would tend to underestimate any protective effect of male circumcision. We minimised this bias where possible b $^{25} 4853$ by excluding individuals who were circumcised after first sexual intercourse or after the age of 11 . However, this information was not available for all studies, including those from Mwanza where many men are circumcised in their late teens or early twenties. ${ }^{11}$ The largest syphilis study from Mwanza ${ }^{49}$ pooled results from three studies and thus contributed more weight to the meta-analysis than if the three studies had been analysed individually.

The participation rates in several studies were low. If participation was differential with respect to circumcision status and STIs, this could either overestimate or underestimate the association, although this seems unlikely.

Prevalence of male circumcision varies with ethnicity, and different ethnic groups may also differ with respect to sexual behaviours. Residual confounding may therefore have affected the results. However, sensitivity analyses showed that adjustment for confounding had little effect on the results for either HSV-2 or syphilis.

There was little evidence of publication bias for studies of HSV-2. For syphilis, there was some indication that smaller studies tended to find larger associations. The asymmetry of the funnel plot (fig 3B) is partly because of the influence of the paper by Buve et al, ${ }^{53}$ where there were no cases of syphilis among the circumcised men. The objective of this paper was to look generally at risk factors among both men and women for gonorrhoea, chlamydia and syphilis, and so publication bias as the result of the association of circumcision and syphilis is implausible. Most of the included studies did not have circumcision as the primary exposure of interest. However, the other two studies with a large association ${ }^{51}{ }^{54}$ did have as their main hypothesis the relation between circumcision and STIs, and may have been susceptible to publication bias.

As many of the above potential biases would tend to bias our summary RR towards the null, our results may be a conservative estimate of a true protective association of male circumcision and STIs.

\section{Biological rationale for association}

There are clear biological reasons why circumcision may protect against both bacterial and viral STIs. The warm, moist area under the foreskin may provide a suitable location in which the pathogens can replicate. Further, uncircumcised men may be at increased risk as the result of entry of pathogens through the inner surface of the foreskin and frenulum, or through micro-abrasions occurring during intercourse. The physical location of ulcers may also affect the role of circumcision on infection. For example, chancroid lesions frequently occur on the external and internal surfaces of the foreskin ${ }^{9162}$ and circumcision may therefore be more protective against chancroid than against syphilis and herpes, where lesions tend to be found more widely on the male genitalia.

Previous studies have found a strongly reduced risk of HIV among circumcised men. ${ }^{14-16}$ In contrast, we found a weak association with HSV-2 infection. This difference may result from different mechanisms of infection for the two viruses. The inner and outer epithelia of the foreskin are composed mainly of keratinocytes, and the inner mucosal layer is rich in Langerhans cells ${ }^{18}$ and CD4+ T helper lymphocytes, especially during infection. ${ }^{17} \mathrm{HSV}$ replicates largely in the epithelial cells

\section{Key messages}

- Results support the common belief that circumcised men are at lower risk of syphilis and chancroid

- Evidence for a protective effect of male circumcision on HSV-2 infection is weak and contrasts with a strong, consistent effect seen against HIV infection

- If male circumcision is promoted as an HIV prevention measure in the future, an added benefit would be protection against ulcerative STI

but also infects Langerhans and other dendritic cells and both stimulates and inhibits their immune function. ${ }^{63}$ Circumcision results in a smaller surface area for infection, but also fewer immune cells to respond against HSV. HSV-2 is shed more widely from the female genital tract than HIV, and there are several portals of entry in female-male transmission besides the foreskin. The role of the foreskin on HSV-2 infection may thus be relatively minor.

In contrast, HIV does not infect the epithelial cells but infects CD4+ lymphocytes, macrophages and some dendritic cells. ${ }^{64}$ HIV also binds passively to the surface of dendritic cells that, upon migration to lymph nodes, deliver the virus to susceptible CD4+ T cells. ${ }^{65}$ Circumcision may thus reduce risk of HIV infection in two ways. Firstly, absence of a foreskin may directly decrease the risk of HIV infection by removing a rich source of CD4+ T cells and Langerhans cells. Secondly, if the foreskin provides a niche for ulcerative STIs, those lesions may afford greater accessibility of HIV to local macrophages and lymphocytes by destroying the integrity of the mucosa and by provoking an immune response.

\section{Implications of these results}

Results from the first randomised controlled trial of male circumcision have shown a strongly protective effect on HIV incidence among South African men. ${ }^{16}$ Two further trials are under way in Uganda and Kenya. If these trials also show a clear effect of male circumcision on HIV, it may be introduced as an HIV prevention measure in populations at high HIV risk. Our results indicate that such an intervention in high risk populations could also provide a direct benefit in reducing risk of STIs (which themselves carry a substantial public health burden), as well as indirect protection against HIV by lowering STI prevalence. Our results will also be useful for ongoing modelling studies of the spread of HIV in populations.

\section{ACKNOWLEDGEMENTS}

We thank the following for contributing information and additional data analysis for this review: Bertran Auvert (INSERM U88, Paris, France), Anne Buve (ITM Antwerp, Belgium); Sami Gottlieb (CDC, Atlanta, Georgia USA); Ron Gray, Xianbin Lin, Michael Chen (Bloomberg School of Public Health, Baltimore, USA); Katherine Thomas, King Holmes, Jorge Sanchez, Javier Lama (University of Washington, Seattle, USA); Jim Todd (LSHTM, London, UK). We also thank Laura Rodrigues and Robin Weiss for helpful comments on the manuscript.

\section{CONTRIBUTORS}

All authors participated in the study planning and design; HAW, SM, and ST conducted the systematic review and data extraction; HAW conducted the statistical analysis and was the lead writer; and all authors provided detailed comments on the paper.

\section{Authors' affiliations}

H A Weiss, S L Thomas, R J Hayes, Infectious Diseases Epidemiology Unit, London School of Hygiene and Tropical Medicine, London, UK 
S K Munabi, General Virology Division, Uganda Virus Research Institute, Uganda

\section{REFERENCES}

1 Remondino PC. History of circumcision from the earliest times to the present Popular edition (unabridged), eds. Philadelphia, London: The FA Davis Co, 1891.

2 Fredman RM. Neonatal circumcision: a general practitioner survey. Med J Aust 1969;1:117-20.

3 Wilson RA. Circumcision and venereal disease. Can Med Assoc J 1947; 56:54-6.

4 American Academy of Pediatrics. Circumcision policy statement. Task Force on Circumcision. Pediatrics 1999:103:686-93.

5 Hutchinson J. On the influence of circumcision in preventing syphilis. Med Times Gazette 1855;32:542-3.

6 Parker JD, Banatvala JE. Herpes genitalis; clinical and virological studies. $\mathrm{Br} J$ Vener Dis 1967:43:212-16.

7 Hand EA. Circumcision and venereal disease. Arch Dermatol Syphilol 1949;60:341-6.

8 Asin J. Chancroid; a report of 1,402 cases. Am J Syph Gonorrhea Vener Dis 1952;36:483-7.

9 Hammond GW, Slutchuk M, Scatliff J, et al. Epidemiologic, clinical, laboratory, and therapeutic features of an urban outbreak of chancroid in North America. Rev Infect Dis 1980;2:867-79.

10 Green EC, Zokwe B, Dupre JD. Indigenous African healers promote male circumcision for prevention of sexually transmitted diseases. Trop Doc 1993:182-3.

11 Nnko S, Washija R, Urassa M, et al. Dynamics of male circumcision practices in northwest Tanzania. Sex Transm Dis 2001;28:214-18.

12 Moses S, Bailey RC, Ronald AR. Male circumcision: assessment of health benefits and risks. Sex Transm Infect 1998;74:368-73.

13 Van Howe RS. Does circumcision influence sexually transmitted diseases? : a literature review, BJU Int 1999;83(Suppl 1):52-62.

14 Weiss HA, Quigley MA, Hayes RJ. Male circumcision and risk of HIV infection in sub-Saharan Africa: a systematic review and meta-analysis. AIDS 2000; 14:2361-70

15 Siegfried N, Muller M, Volmink J, et al. Male circumcision for prevention of heterosexual acquisition of HIV in men. Cochrane Database Syst Rev 2003:CD003362

16 Auvert B, Puren A, Taljaard D, et al. Impact of male circumcision on the female-to-male transmission of HIV (Abstract TuOa0402). 3rd IAS Conference on HIV Pathogenesis and Treatment. Rio De Janeiro, 2005.

17 Patterson BK, Landay A, Siegel JN, et al. Susceptibility to human immunodeficiency virus- 1 infection of human foreskin and cervical tissue grown in explant culture. Am J Pathol 2002;161:867-73.

18 Szabo R, Short RV. How does male circumcision protect against HIV infection? BMJ 2000;320:1592-4.

19 McCoombe SG, Cameron PU, Short RV. How HIV enters the human penis. The XV International AIDS Conference. Vol. eJIAS. 2004 Jul 11;1(1): MoPeA3048, Bangkok, 2004

20 Peeling RW, Ye H. Diagnostic tools for preventing and managing maternal and congenital syphilis: an overview. Bull World Health Organ 2004;82:439-46.

21 DerSimonian R, Laird N. Meta-analysis in clinical trials. Control Clin Trials 1986;7:177-88.

22 Begg CB, Mazumdar M. Operating characteristics of a rank correlation test for publication bias. Biometrics 1994;50:1088-101.

23 Intercooled Stata 8.2 for Windows. College Station, TX, 2004

24 Gottlieb SL, Douglas JM Jr, Foster M, et al. Incidence of herpes simplex virus type 2 infection in 5 sexually transmitted disease (STD) clinics and the effect of HIV/STD risk-reduction counseling. J Infect Dis 2004;190:1059-67.

25 Gray R, Azire J, Serwadda D, et al. Male circumcision and the risk of sexually transmitted infections and HIV in Rakai, Uganda. AIDS 2004;18:2428-30.

26 Reynolds SJ, Shepherd ME, Risbud AR, et al. Male circumcision and risk of HIV-1 and other sexually transmitted infections in India. Lancet 2004; 363: 1039-40.

27 Barongo LR, Borgdorff MW, Newell JN, et al. Intake of a cohort study of urban factory workers in northwest Tanzania. Risk factors for HIV-1 infection. Trop Geogr Med 1994;46:157-62.

28 Grosskurth H, Mosha F, Todd J, et al. Impact of improved treatment of sexually transmitted diseases on HIV infection in rural Tanzania: randomised controlled trial. Lancet 1995;346:530-6.

29 Kelly R, Kiwanuka N, Wawer MJ, et al. Age of male circumcision and risk of prevalent HIV infection in rural Uganda. AIDS 1999;13:399-405.

30 Rakwar J, Lavreys L, Thompson ML, et al. Cofactors for the acquisition of HIV1 among heterosexual men: prospective cohort study of trucking company workers in Kenya. AIDS 1999;13:607-14.

31 Simonsen JN, Cameron DW, Gakinya MN, et al. Human immunodeficiency virus infection among men with sexually transmitted diseases. Experience from a center in Africa. N Engl J Med 1988;319:274-8.

32 Gottlieb SL, Douglas JM Jr, Schmid DS, et al. Seroprevalence and correlates of herpes simplex virus type 2 infection in five sexually transmitted-disease clinics. J Infect Dis 2002;186:1381-9.

33 Le Bacq F, Mason PR, Gwanzura L, et al. HIV and other sexually transmitted diseases at a rural hospital in Zimbabwe. Genitourin Med 1993:69:352-6.
34 Manjunath JV, Thappa DM, Jaisankar TJ. Sexually transmitted diseases and sexual lifestyles of long-distance truck drivers: a clinico-epidemiologic study in south India. Int J STD AIDS 2002;13:612-17.

35 Rodrigues JJ, Mehendale SM, Shepherd ME, et al. Risk factors for HIV infection in people attending clinics for sexually transmitted diseases in India. BMJ 1995;311:283-6.

36 Sutcliffe S, Taha TE, Kumwenda NI, et al. HIV-1 prevalence and herpes simplex virus 2 , hepatitis $C$ virus, and hepatitis $B$ virus infections among male workers at a sugar estate in Malawi. J Acquir Immune Defic Syndr 2002;31:90-7.

37 Rakwar J, Jackson D, Maclean I, et al. Antibody to Haemophilus ducreyi among trucking company workers in Kenya. Sex Transm Dis 1997:24:267-71

38 Barile MF, Blumberg JM, Kraul CW, et al. Penile lesions among US Armed Forces personnel in Japan. The prevalence of herpes simplex and the role of pleuropneumonia-like organisms. Arch Dermatol 1962;86:273-81.

39 Lloyd VE, Lloyd NL. Circumcision and syphilis. BMJ 1934:144-6.

40 Nasio JM, Nagelkerke NJ, Mwatha A, et al. Genital ulcer disease among STD clinic attenders in Nairobi: association with HIV-1 and circumcision status. Int J STD AIDS 1996;7:410-14.

41 Cameron DW, Simonsen JN, D'Costa $\sqcup$, et al. Female to male transmission of human immunodeficiency virus type 1: risk factors for seroconversion in men. Lancet 1989;2:403-7.

42 Hart G. Venereal disease in a war environment: incidence and management. Med J Aust 1975;1:808-10.

43 Lavreys L, Rakwar JP, Thompson ML, et al. Effect of circumcision on incidence of human immunodeficiency virus type 1 and other sexually transmitted diseases: a prospective cohort study of trucking company employees in Kenya. $J$ Infect Dis 1999; 180:330-6.

44 Obasi A, Mosha F, Quigley M, et al. Antibody to herpes simplex virus type 2 as a marker of sexual risk behavior in rural Tanzania. J Infect Dis 1999; 179:16-24.

45 Weiss HA, Buve A, Robinson NJ, et al. The epidemiology of HSV-2 infection and its association with HIV infection in four urban African populations. AIDS 2001;15(Suppl 4):S97-108.

46 Suligoi B, Tchamgmena O, Sarmati L, et al. Prevalence and risk factors for herpes simplex virus type 2 infection among adolescents and adults in northern Cameroon. Sex Transm Dis 2001;28:690-3.

47 Kapiga SH, Sam NE, Shao JF, et al. Herpes simplex virus type 2 infection among bar and hotel workers in northern Tanzania: prevalence and risk factors. Sex Transm Dis 2003:30:187-92.

48 Auvert B, Ballard R, Campbell C, et al. HIV infection among youth in a South African mining town is associated with herpes simplex virus-2 seropositivity and sexual behaviour. AIDS 2001;15:885-98.

49 Urassa M, Todd J, Boerma JT, et al. Male circumcision and susceptibility to HIV infection among men in Tanzania. AIDS 1997;11:73-80.

50 Todd J, Munguti K, Grosskurth H, et al. Risk factors for active syphilis and TPHA seroconversion in a rural African population. Sex Transm Infect $2001 ; 77: 37-45$

51 Parker SW, Stewart AJ, Wren MN, et al. Circumcision and sexually transmissible disease. Med J Aust 1983;2:288-90.

52 Bwayo J, Plummer $F$, Omari $M$, et al. Human immunodeficiency virus infection in long-distance truck drivers in east Africa. Arch Intern Med 1994; 154:1391-6

53 Buve A, Weiss HA, Laga $M$, et al. The epidemiology of gonorrhoea chlamydial infection and syphilis in four African cities. AIDS 2001;15(Suppl 4):S79-88.

54 Cook LS, Koutsky LA, Holmes KK. Circumcision and sexually transmitted diseases. Am J Public Health 1994;84:197-201.

55 Diseker RA 3rd, Peterman TA, Kamb ML, et al. ircumcision and STD in the United States: cross sectional and cohort analyses. Sex Transm Infect 2000;76:474-9.

56 Tabet S, Sanchez J, Lama J, et al. HIV, syphilis and heterosexual bridging among Peruvian men who have sex with men. AIDS 2002;16:1271-7.

57 Newell J, Senkoro K, Mosha F, et al. A population-based study of syphilis and sexually transmitted disease syndromes in north-western Tanzania. 2. Risk factors and health seeking behaviour. Genitourin Med 1993;69:421-6.

58 Vaz RG, Gloyd S, Folgosa E, et al. Syphilis and HIV infection among prisoners in Maputo, Mozambique. Int J STD AIDS 1995;6:42-6.

59 Van Dyck E, Buve A, Weiss HA, et al. Performance of commercially available enzyme immunoassays for detection of antibodies against herpes simplex virus type 2 in African populations. J Clin Microbiol 2004;42:2961-5.

60 Alfa MJ, Olson N, Degagne P, et al. Humoral immune response of humans to lipooligosaccharide and outer membrane proteins of Haemophilus ducreyi. $J$ Infect Dis 1993;167:1206-10.

61 Kerber RE, Rowe CE, Gilbert KR. Treatment of chancroid. A comparison of tetracycline and sulfisoxazole. Arch Dermatol 1969;100:604-7.

62 Nsanze H, Fast MV, D'Costa U, et al. Genital ulcers in Kenya. Clinical and laboratory study. Br J Vener Dis 1981;57:378-81.

63 Pollara G, Speidel K, Samady L, et al. Herpes simplex virus infection of dendritic cells: balance among activation, inhibition, and immunity. $J$ Infect Dis 2003; 187:165-78

64 Popov S, Chenine AL, Gruber A, et al. Long-term productive human immunodeficiency virus infection of CDla-sorted myeloid dendritic cells. J Virol 2005;79:602-8.

65 Geijtenbeek TB, Kwon DS, Torensma R, et al. DC-SIGN, a dendritic cellspecific HIV-1-binding protein that enhances trans-infection of T cells. Cell 2000; 100:587-97. 